\title{
USO ALTERNADO DE MÉTODOS MECÂNICOS E QUIMMCOS DE CONTROLE DE ERVAS DANINHAS EM CAFEZAL $\left(^{1}\right)$
}

GASTÁo MORAES DA SILVEIRA (2), Secto de Máquinas de Movimentaçāo do Solo, SERGIO AUGUSTO HIROAKI KURACHI (2), Seçāo de Projetos e Materiais, MAMOR FUJIWARA, Secão de Cafe, e EDUARDo FENZ (3). Divisāo de Engenharia Agricola, Instituto Agronómico.

\section{RESUMO}

Estuda-se, no presente trabalho, a integração de métodos mecânicos (grade, enxada rotativa, roçadeira) com químicos (herbicidas), comparando-os com a capina manual, em tratamentos feitos alternadamente, procurando evitar inconvenientes já observados pelo uso sistemático de determinados implementos. Após cinco anos, não se notou diferença estatisticamente significativa entre as diversas combinações de implementos utilizados (enxada rotativa-herbicida; roçadeira-enxada rotativa; roçadeira-grade e roçadeira nas águas-herbicida na seca), assim como inconvenientes surgidos pelo seu uso sistemático.

\section{INTRODUÇÃO}

O café é ainda o principal produto agrícola brasileiro de exportação, sendo a base de riqueza de vários estados, especialmente de São Paulo.

Na década de 70 , a cultura passou por sucessivas crises. O aparecimento da ferrugem do cafeeiro em nosso meio e, principalmente, as adversidades climáticas, obrigaram os cafeicultores e o governo a se empenharem na renovação do parque cafeeiro nacional, estimulando o plantio e a adoção de técnicas de condução de cultura mais atualizadas para a obtenção de maior produtividade.

O êxodo rural e a implantação de leis trabalhistas no campo tornam a capina manual do cafezal uma operação onerosa, pela inexistência do braço operário, re-

(1) Recebido para publicação a $1^{9}$ de outubro de 1980.

(2) Com bolsa de suplementação do CNPq.

(3) Engenheiro-Agrônomo. Bolsista do IBC. 
sultando, por falta de controle, num desenvolvimento rápido e completo das ervas daninhas.

Em tal conjuntura, uma saída econômica, tanto para o médio como para o grande produtor, é a mecanização de sua lavoura; nesse caso, o controle de ervas daninhas é de suma importância, em vista da quantidade de mão-de-obra que absorve.

No presente trabalho, estudam-se alguns métodos de controle de ervas daninhas, enfatizando a sua mecanização; realiza-se uma integração de métodos mecânicos e químicos, fazendo os tratamentcs alternadamente, procurando evitar inconvenientes já observados por SILVEIRA et alii (17) com o uso continuado de um só tipo de equipamento ou tratamento. Observou-se que o uso sistemático da grade, enxada rotativa e herbicida concorre para um aumento de erosão. Isso pode ser evitado, empregando-se alternadamente as várias máquinas.

A eficiência das diversas combinaçōes de implementos foi avaliada através de controle de produção.

\section{REVISÃO BIBLIOGRÃFICA}

KRASNIANSKY (6), em ensaios de controle de ervas daninhas em cafezais no antigo Congo Belga, conseguiu os melhores resultados com o uso combinado de implementos: primeiro enxada rotativa e depois grade de discos.

BUTTERS \& CLEGG (2) estabeleceram, de acordo com a épo- ca do ano, uma seqüência de operações de cultivos e, estudando o seu custo, concluíram que o uso de máquinas reduz o preço da capina à metade quando comparada à manual.

REYNOLDS (14) verificou, com os dados de produção no período 1962-1965, que o tratamento com capina mínima produziu $45 \%$ menos, e o de ervas daninhas ceifadas $53 \%$, em relação às parcelas mantidas completamente no limpo. Verificou também que, enquanto as pulverizações de cobre para controle da ferrugem aumentaram a produção em $21,6 \mathrm{~kg} / \mathrm{ha}$, a manutenção da cultura livre de mato aumentou-a para $20,5 \mathrm{~kg} / \mathrm{ha}$, dando assim uma idéia da importância do controle das ervas daninhas.

OUTRAM (12) faz referências ao herbicida paraquat: extermina a maioria da vegetação verde com a qual entra em contacto, tendo, porém, pouca translocação; quando aplicado em ervas daninhas perenes, estas podem brotar novamente através de seus sistemas radiculares.

MITCHELL (8) estudou a combinação de vários herbicidas, capina a mão, enxada rotativa e cobertura morta. Nos quatro primeiros anos, as aplicações de herbicidas não produziram efeitos significativos na produção, quando comparada com os demais tratamentos.

AUSTIN (1) mostrou que, enquanto o custo da capina com herbicida é elevado no primeiro ano, nos anos seguintes ela fica mais barata em relaçāo à enxada 
ou ao cultivador mecânico. Quanto às aplicações de pós-emergência, o sistema mais econômico é a pulverização quando as ervas daninhas não passam de 10 a $15 \mathrm{~cm}$ de altura, exigindo menor dosagem dos produtos químicos. O melhor sistema de cultivo mínimo é o uso de cobertura morta e herbicida, sendo o mato pulverizado quando emergia da cobertura.

O C.E.E.M.A.T. (3) recomenda como proceder ao cultivo mecânico das ervas daninhas em cafezais. Os implementos montados sāo mais práticos do que os tracionados. O cafezal deverá ter espaçamento entre linhas de $3,5 \mathrm{~m}$, no mínimo, sendo o ideal $4,0 \mathrm{~m}$. Os tratores estreitos ou tipo vinhateiro, com carenagem, deverão ser preferidos. O cultivo mecânico será aplicado nas entrelinhas e, o manual, na linha. Recomenda também o uso de grade de disco ou enxada rotativa, bem como a aplicação de cobertura morta, aconselhando nunca deixar o solo completamente desprotegido.

MORAES (10), estudando a fitotoxicidade de diversos herbicidas, observou que eles promoveram danos reduzidos quando a aplicação foi dirigida ao solo.

GALLO et alii (4) estudaram a absorção de nutrientes pelas ervas daninhas e sua competição com o cafeeiro. O potássio e o nitrogênio foram os elementos extraídos do solo em maiores quantidades pelas ervas daninhas. Quanto a micronutrientes, a ex- tração de zinco desperta interesse, enquanto a competição por boro poderá ocorrer em áreas localizadas.

MORAES (9) efetuou estudos focalizando a combinação de herbicidas para desmatamento em cafezal, chegando às seguintes conclusões: a) nas condiçōes de solo (latossolo roxo) e clima (anos relativamente fracos em precipitações pluviais) em que foi conduzido o ensaio, tanto os herbicidas residuais como os de pós-emergência funcionaram satisfatoriamente, do ponto de vista de desmatamento; b) nenhum dos tratamentos de herbicidas excluiu totalmente a utilização da enxada; c) durante o decorrer do experimento, foram feitas duas aplicaçōes de herbicidas anualmente, uma no fim das chuvas e outra no fim ou no começo do ano; d) durante o lapso de tempo, de três anos, nos tratamentos com herbicidas, foram suficientes quatro capinas de bico de enxada para a complementação dos trabalhos de desmatamento; e) dos herbicidas de pré-emergência utilizados, o diuron foi o que melhor resultado apresentou no desmatamento, enquanto das combinações, aquela em que entrou o diuron juntamente com o 2,4-D + TCA, foi a melhor.

MARQUES ( $\boldsymbol{\gamma}$ ) sugere o controle do desenvolvimento das plantas daninhas ceifando-as com alfanje manual ou roçadoras. Como a ceifa não destrói completamente o mato, o seu número precisa ser quase que o dobro do número de capinas. 
MORAES et alii $\left(^{4}\right)$ concluiram que não houve diferenças entre capina manual e cultivo mecânico, no controle de ervas daninhas em cafezal: mas, os dois tratamentos produziram o dobro em relação ao mato apenas ceifado.

MORAES et alii (11) determinaram em 45 dias espaço de tempo ideal entre uma capina e a seguinte.

\section{MATERIAL E MÉTODOS}

Abrangem as máquinas, o solc e os ensaios de campo.

\subsection{Máquinas}

Os equipamentos usados alternadamente no controle das ervas daninhas são: grade de discos, enxada rotativa, roçadeira e aplicador de herbicidas. Os resultados são comparados com os da capina manual, através de controle de produçã̉o.

Grade: é utilizada uma grade de discos de dupla ação, com dois corpos, tendo oito discos de dezoito polegadas em cada corpo, desenvolvida por SILVEIRA et alii (18), sendo os discos frontais recortados e os traseiros lisos.

Enxada rotativa: emprega-se um modelo com 1,30m de largura de corte, com cinco flanges, ten-

(4) MORAES, M. V.; BERTONI, J.; MENDES, J. E. T.; REIS, A. J.; CASTRO, G. A. Efeito, na produção, de práticas conservacionistas de caráter vegetativo em cafezal. Campinas, Relatório da Seção de Conservação do Solo, Instituto Agronômico, 1956/57. p. 98-99. (Não publicado) do as laterais três facas e as três centrais, seis facas. A rotação de trabalho pode ser variada mediante mudanças na combinação de engrenagens, localizadas em uma caixa de mudança existente na parte posterior do equipamento.

Roçadeira: o implemento empregado é um protótipo deslocado em relação ao trator, procurando-se cortar o mato próximo ao tronco da árvore, embaixo da saia" do pé de café. Suas principais características são: largura de corte $1,30 \mathrm{~m}$; deslocamento $0,25 \mathrm{~m}$ à esquerda em relação ao trator; rotação das facas: 1.100 rpm; peso: $255 \mathrm{~kg}$ (16).

Herbicida: foi aplicado com pulverizador acoplado ao sistema de engate por três pontos e acionado pela tomada de potência do trator. Utilizaram-se produtos à base de paraquat em pós-emergência, a 2,5 litros/hectare da formulação.

\subsection{Solo}

O experimento está instalado em solo podzólico vermelho-amarelo orto, na Fazenda Brejão, município de São João da Boa Vista (SP), em terreno com cerca de $4 \%$ de declividadade.

$O$ estudo das modificações estruturais sofridas pelo solo, com o emprego de diferentes métodos de cultivo e seus efeitos sobre o comportamento da planta, assim como os efeitos da compactação, foram avaliados em outro trabalho (15). 


\subsection{Ensaios de campo}

O café, cultivar mundo novo, plantado no espaçamento de 4,00 $\times 2,00 \mathrm{~m}$, com duas plantas por cova, tinha, na época de instalação do experimento, três anos de idade.

No controle da ferrugem, foram feitas treze pulverizaçōes durante os cinco ciclos (1977/1981). Usou-se oxicloreto de cobre a $50 \%$ na dosagem de $4,0 \mathrm{~kg}$ do produto por 1.000 covas. Além do oxicloreto, empregaram-se esporadicamente os micronutrientes zinco e boro, em consequiência de deficiências apresentadas pela lavoura. $O$ sulfato de zinco foi utilizado a 4,0kg e, o ácido bórico, a 2,0kg por 1.000 covas. Os tratamentos foram efetuados com equipamentos acoplados a trator, com volume de 300 litros por 1.000 covas. As adubações foram as de rotina.

Nos ensaios, determinou-se o número de capinas necessárias durante um ano agricola, assim como o espaçamento entre as capinas, relacionado com cada tipo de implemento.

Em cada capina, para determinado implemento anotaram-se os seguintes dados:

- Trator: marca, tipo, marcha de operação e velocidade;

- Implemento: capacidade teórica de trabalho, capacidade efetiva de trabalho, largura, profundidade (grade e enxada rotativa), altura do corte (roçadeira) e número de passagens para tratamento de uma rua;

- Observações sobre a qualidade do trabalho.
O delineamento experimental é de blocos ao acaso, com cinco tratamentos e seis repetições. Cada parcela compōe-se de uma linha de café com cinqüenta plantas, sendo que o implemento trabalha nas duas ruas adjacentes a cada linha. Desse modo, entre duas linhas consecutivas, há uma de bordadura, que é cultivada de ambos os lados, com implementos diferentes. Os tratamentos são aplicados somente nas ruas. Nas linhas, entre plantas, o cultivo é feito sempre com enxada manual.

O controle da produção é realizado, colhendo-se café das vinte plantas centrais de cada linha, e expresso em quilogramas de café beneficiado.

\section{RESULTADOS E DISCUSSÃO}

O experimento foi instalado em outubro de 1976. São apresentados dados de produção de cinco anos (1977/1981). Em agosto de 1981, o cafezal do experimento sofreu uma forte geada, o que impediu a continuaçāo dos trabalhos, uma vez que parte da lavoura foi "decotada" e parte "recepada".

Os dados referem-se às produçōes e ao desempenho de campo dos implementos.

\section{4,1. Dados de produção}

Referem-se à produção média em quilogramas de café beneficiado por parcela de vinte plantas e constam do quadro 1 .

No quadro 2 constam as análises das variâncias relativas aos dados de produção do quadro 1 . 
QUADRO 1 - Produções médias em quilogramas de café beneficiado por parcelas de vinte plantas, obtidas em anos consecutivos em ensaio de uso alternado de métodos mecânicos e químicos, no controle de ervas daninhas em cafezal 'mundo novo' instalado em solo podzólico vermelho-amarelo, orto, São João da Boa Vista (SP)

\begin{tabular}{|c|c|c|c|c|c|c|c|}
\hline \multirow{2}{*}{ Tratamento } & \multicolumn{6}{|c|}{ Bloco } & \multirow{2}{*}{ Média } \\
\hline & I & II & III & IV & $\mathbf{V}$ & VI & \\
\hline \multicolumn{8}{|c|}{ Biênio $1977 / 1978$} \\
\hline $\begin{array}{l}\text { Testemunha (ca- } \\
\text { pina manual) }\end{array}$ & 41,58 & 52,92 & 43,36 & 49,66 & 63,21 & 33,70 & 47,40 \\
\hline $\begin{array}{l}\text { Enxada rotativa- } \\
\text {-herbicida }\end{array}$ & 48,10 & 49,98 & 52,39 & 38,95 & 46,09 & 46,62 & 47,02 \\
\hline $\begin{array}{l}\text { Roçadeira-en- } \\
\text { xada rotativa }\end{array}$ & 36,22 & 39,27 & 57,01 & 49,14 & 37,06 & 46,09 & 44,13 \\
\hline $\begin{array}{l}\text { Roçadeira- } \\
\text {-grade }\end{array}$ & 45,99 & 47,88 & 46,62 & 52,92 & $\mathbf{5 7 , 9 6}$ & 49,77 & 50,19 \\
\hline $\begin{array}{l}\text { Roçadeira nas } \\
\text { águas-herbicida } \\
\text { na seca. }\end{array}$ & 40,95 & 40,63 & 43,89 & 52,18 & 47,04 & 54,81 & 46,58 \\
\hline
\end{tabular}

Biênio 1979/1980

\begin{tabular}{|c|c|c|c|c|c|c|c|}
\hline $\begin{array}{l}\text { Testemunha (ca- } \\
\text { pina manual) }\end{array}$ & 65,20 & 72,97 & 63,90 & 64,60 & 63,80 & 65,74 & 66,03 \\
\hline $\begin{array}{l}\text { Enxada rotativa- } \\
\text {-herbicida }\end{array}$ & 68,66 & 60,09 & 58,00 & 63,40 & 67,50 & 66,00 & 63,94 \\
\hline $\begin{array}{l}\text { Rocadeira-en- } \\
\text { xada rotativa }\end{array}$ & 62,72 & 64,24 & 71,96 & 79,99 & 63,64 & 68,43 & 68,49 \\
\hline $\begin{array}{l}\text { Roçadeira- } \\
\text {-grade }\end{array}$ & 59,65 & 74,77 & 82,47 & 79,84 & 71,90 & 72,30 & 73,48 \\
\hline $\begin{array}{l}\text { Roçadeira nas } \\
\text { águas-herbicida } \\
\text { na seca }\end{array}$ & 60,14 & 67,80 & 60,44 & 58,48 & 67,36 & 81,15 & 65,89 \\
\hline \multicolumn{8}{|c|}{ ANO 1981} \\
\hline $\begin{array}{l}\text { Testemunha (ca- } \\
\text { pina manual) }\end{array}$ & 78,10 & 97,48 & 72,68 & 99,53 & 79,38 & 97,57 & 87,45 \\
\hline $\begin{array}{l}\text { Enxada rotativa- } \\
\text {-herbicida }\end{array}$ & 83,95 & 78,93 & 78,38 & 84,64 & 102,49 & 88,01 & 86,06 \\
\hline $\begin{array}{l}\text { Roçadeira-en- } \\
\text { xada rotativa }\end{array}$ & 92,76 & 94,53 & 84,47 & 79,89 & 94,56 & 111,42 & 92,93 \\
\hline $\begin{array}{c}\text { Roçadeira- } \\
\text {-grade }\end{array}$ & 84,82 & 74,25 & 116,51 & 94,13 & 119,38 & 107,88 & 99,49 \\
\hline $\begin{array}{l}\text { Roçadeira nas } \\
\text { águas-herbicida } \\
\text { na seca }\end{array}$ & 84,58 & 64,20 & 100,67 & 118,83 & 102,51 & 90,24 & 93,50 \\
\hline
\end{tabular}


QUADRO 2 - Análise de variância dos dados do quadro 1

\begin{tabular}{lrccc}
\hline Fonte de variação & G.L. & S.Q. & Q.M. & F. \\
\hline & & a) Biênio & $1977 / 1978$ \\
& 5 & 184,5626 & 36,9125 \\
Blocos & 4 & 112,3172 & C.V. $=9,83 \%$ \\
Tratamentos & 20 & 1052,1419 & 52,6070 \\
Residuo & 29 & 1349,0217 & & \\
Total & & $\mathrm{s}=7,2530$ & C.V. $=15,4 \%$ \\
Média geral $\mathrm{m}=47,07$ & &
\end{tabular}

\begin{tabular}{|c|c|c|c|c|}
\hline \multicolumn{5}{|c|}{ b) Biênio $1979 / 1980$} \\
\hline Blocos & 5 & 160,0447 & 32,0089 & \multirow{3}{*}{1,84 n.s } \\
\hline Tratamentos & 4 & 325,2721 & 81,3180 & \\
\hline Resíduo & 20 & 883,6525 & 44,1826 & \\
\hline Total & 29 & 1368,9693 & & \\
\hline \multirow[t]{2}{*}{ Média geral $\mathrm{m}=67,57$} & & $s=6,6470$ & 28,0793 & $\theta, 53$ n.s. \\
\hline & \multicolumn{3}{|c|}{ c) Ano 1981} & \multirow{6}{*}{ 0,94 n.s. } \\
\hline Blocos & 5 & 1377,0437 & 275,4087 & \\
\hline Tratamentos & 4 & 690,6533 & 172,6633 & \\
\hline Resíduo & 20 & 3680,9340 & 184,0467 & \\
\hline Total & 29 & 5748,6310 & & \\
\hline Média geral $\mathrm{m}=91,89$ & & $s=13,5663$ & C.V. $=$ & \\
\hline
\end{tabular}

Pela análise da variância dos dados do biênio $1977 / 78$, observa-se que estatisticamente não há diferença entre os tratamentos. O mesmo ocorre com os dados do biênio 1979/80 e do ano 1981, em que também não há diferença estatisticamente significativa entre os tratamentos.

\subsection{Dados relativos ao desempe- nho dos implementos utiliza- dos nos trabalhos de campo}

No quadro 3 constam os dados comparativos dos vários tratamentos estudados no qüinqüênio 1977/1981.

A capina entre as plantas, nas linhas, foi feita a enxada, gastan- do-se dezoito homens/hora por 1.000 covas, para as combinações de tratamentos: enxada rotativa-herbicida; roçadeira-rotativa e roçadeira-grade; já para o tratamento roçadeira nas águas-herbicidas na seca, o gasto foi 24 homens-hora/1.000 covas.

A altura média de corte da roçadeira nas várias aplicaçōes foi C,06m.

Levando em consideração o objetivo deste estudo, realizou-se a análise dos dados de produção. Com a alternância no uso dos equipamentos, evitou-se o problema da formação de "degraus" entre a linha de plantas e o local onde foram passadas a grade $e$ 
QUADRO 3 - Dados relativos ao desempenho de implementos e tratamentos utilizados no controle alternado de ervas daninhas em cafezal em solo podzólico vermelho-amarelo, orto, São João da Boa Vista (SP), 1977/1981

\begin{tabular}{|c|c|c|c|c|}
\hline Tratamento & $\begin{array}{l}\text { Número de } \\
\text { aplicações }\end{array}$ & $\begin{array}{l}\text { Capacidade do trabalho } \\
\text { homens-hora } / 1.000 \text { covas }\end{array}$ & $\begin{array}{l}\text { Profun- } \\
\text { didade }\end{array}$ & $\begin{array}{l}\text { Lar- } \\
\text { gura }\end{array}$ \\
\hline & & & $\mathrm{m}$ & $\mathrm{m}$ \\
\hline Enxada & 20 & 90,0 & - & - \\
\hline Enxada rotativa- & 14 & 1,6 & 0,07 & 1,22 \\
\hline -herbicida & 10 & 1,0 & - & 3,20 \\
\hline Roçadeira- & 12 & 1,5 & - & 1,25 \\
\hline -enxada rotativa & 13 & 1,6 & 0,07 & 1,22 \\
\hline Roçadeira- & 13 & 1,5 & - & 1,25 \\
\hline -grade & 14 & 1,3 & 0,07 & 0,95 \\
\hline Roçadeira nas äguas- & 23 & 1,5 & - & 1,25 \\
\hline -herbicida na seca & 5 & 1,0 & - & 3,20 \\
\hline
\end{tabular}

a enxada rotativa e aplicado o herbicida, conforme observado por SILVEIRA et alii (17).

Os resultados obtidos até agora indicam a conveniência da alternância no uso dos equipamentos, de acordo com KRASNIANSKY (6), embora em nosso trabaIho não tenhamos usado a alternância enxada rotativa-grade. Estes implementos revolvem o solo e usados em seqüência poderão causar problemas de erosão no período das águas.

PEREIRA \& JONES (13), JONES \& WALLIS (5), REYNOLDS (14) e MORAES et alii (') observaram que a permanên-

(4) MORAES, M. V.; BERTONI, J.; MENDES, J. E. T.; REIS, A. J.; CASTRO, G. A. Efeito, na produção, de práticas conservacionistas de caráter vegetativo em cafezal. Campinas, Relatório da Seção de Conservação do Solo, Instituto Agronômico, 1956/57. p. 98-99. (Não publicado) cia do mato roçado na cultura durante todo o ano, diminuiu significativamente a produção. No presente trabalho isso não ocorreu, pois o uso de herbicida na seca impediu a concorrência das ervas más com a cultura, principalmente no que diz respeito à água. Entretanto, o uso de roçadeiras nas águas-herbicidas na seca foi $o$ tratamento usado mais vezes, confirmando MARQUES ( $\boldsymbol{y}$ ).

Por outro lado, observando os dados do quadro 3 , pode-se notar a economia de mão-de-obra conseguida com a mecanização do controle de ervas daninhas.

Os tratamentos mecanizados empregados em menor número de vezes foram: enxada rotativa-herbicida; roçadeira-enxada rotativa; roçadeira-grade e roçadeira nas águas-herbicidas na seca. 


\section{CONCLUSÕES}

a) Para as condiçōes do presente trabalho, quanto à produção, não houve diferença estatisticamente significativa entre os diversos implementos usados alternadamente no controle das ervas daninhas. Não se observaram também sinais de erosão superficial. b) Com a mecanização, consegue-se uma grande economia de mão-de-obra no controle de ervas daninhas em cafezal.

c) Dos tratamentos mecanizados, a combinação enxada rotativa-herbicida foi a utilizada em menor número de vezes.

\section{SUMMARY}

\section{ALTERNATE USE OF MECHANICAL AND CHEMICAL METHODS OF WEED CONTROL IN COFFEE CRAP}

The use of several methods of weed control (disc-harrow, rotary cultivator, off-set rotary shredder and herbicide) was studied and compared with hand cultivation. The treatments were made alternatively, trying to prevent the inconveniences observed when certain machines were sistematically used. After five years of observations, no significant statistical difference was noticed among several combinations: a) off-set rotary shredder versus herbicide; b) off-set rotary shredder versus rotary cultivator; c) off-set rotary shredder versus disc harrow; d) off-set rotary shredder (in the rain season) versus herbicide (in the dry season).

\section{AGRADECLMENTOS}

Os autores agradecem ao Sr. Carlos Coelho Neto, proprietário da Fazenda Brejão, as facilidades oferecidas durante a condução dos trabalhos.

\section{REFERENCIAS BIBLIOGRAFICAS}

1. AUSTIN, J. S. F. The possibility of minimal cultivation in coffee with "Gramoxone". Tanganyka Coffee News. April/June, 1968.

2. BUTTERS, B. \& CLEGG, D. E. H. Improved methods of weed control in robusta coffee in Uganda. East African Agricultural and Foresty Journal, 29(1):67-71, 1963.

3. CENTRE D'ÊTUDES ET D'EXPERIMENTATTON DU MACHINISME AGRICOLE TROPICAL (C.E.E.M.A.T.). Note succint sur les types de matériels utilizables pour l'entre tien motorisé des plantations de cafeiers. 1970. 5p.

4. GALLO, J. R.; MORAES, F. R. P. de.; LOTT, W. L.; INFORZATO, R. Absorção de nutrientes pelas ervas daninhas e sua competição com o cafeeiro. 2ed. Campinas, Instituto Agronômico, 1963. (Boletim, 104)

5. JONES, P. A. \& WALLIS, J. A. M. A tillage study in Kenya coffee. Part III. Empire Journal of Experimental Agriculture, 31:243, 1963.

6. KRASNIANSKY, V. La mécanisation de la caféiculture dans l'Ubangi. Bulletin du Comptoir de Vente des Cafés du Congo, 9(109):20-25, 1956.

7. MARQUES, J. Q. A. Conservação do solo em cafezal. São Paulo, Superintendência dos Serviços do Café, 1950. 233p.

8. MITCHELL, H. W. The possibility of weed control with minimal cultivation. Kenya Coffee, 32:232, 1967. 
9. MORAES, M. V. Ensaios de combinações de herbicidas para desmatamento de cafezal. Separata de SEMINARIO BRASILEIRO DE HERBICIDAS E ERVAS DANINHAS, 5., Cruz das Almas, BA, 1964. Anais. Cruz das Almas, Instituto de Pesquisas e Experimentação Agropecuárias do Leste, 1964. p.207-215.

10. Estudo da fitotoxidade de diversos herbicidas do cafeeiro. Separata de SEMINĀRIO BRASILEIRO DE HERBICIDAS E ERVAS DANINHAS, 4., Rio de Janeiro, 1962. Anais. p.261-279.

11. - ; TOLEDO, S. V.; BRILHO, C. C.; FTGUEIREDO, J. L.; ALVES, A. Ensaio do número de capinas para o cafeeiro. Separata de SEMTNAâRIO BRASILEIRO DE HERBICIDAS E ERVAS DANINHAS, 6., Sete Lagoas, MG, 1966. Anais. p.187-192.

12. OUTRAM, D. J. Weed control. Kenya Coffee, 32:19, 1967.

13. PEREIRA, H. C. \& JONES, P. A. A tillage study in Kenya coffee. Part II. Empire Journal of Experimental Agriculture, 22:232, 1954.

14. REYNOLDS, R. A. C. The investigation of weed control in a West Rift Coffee area. Kenya Coffee, 32:186, 1967.

15. SIlveIrA, G. M. da. Métodos de cultivo em cafezal e a estrutura do solo. Campinas, Instituto Agronômico, 1981. 9p. (Boletim Técnico, 70)

16. Roçadeira deslocada. Campinas, Instituto Agronômico, $1975.7 \mathrm{p}$. (Circular, 43)

17. —, G. M. da; KURACHI, S. A. FUJIWARA, M. Comparação de métodos mecânicos e químicos, no controle de ervas daninhas em cafezal. O Agropômico, Campinas, 29/30:137-148, 1978.

18. — FUJIWARA, M.; KURACHI, S. A. H. Grade para capina de cafezal. Campinas, Instituto Agronômico, 1977. 5p. (Circular, 67) 